\title{
Adult Romantic Attachment: Theoretical Developments, Emerging Controversies, and Unanswered Questions
}

\author{
R. Chris Fraley and Phillip R. Shaver \\ University of California, Davis
}

\begin{abstract}
The authors review the theory of romantic, or pair-bond, attachment as it was originally formulated by C. Hazan and P. R. Shaver in 1987 and describe how it has evolved over more than a decade. In addition, they discuss 5 issues related to the theory that need further clarification: (a) the nature of attachment relationships, (b) the evolution and function of attachment in adulthood, (c) models of individual differences in attachment, (d) continuity and change in attachment security, and (e) the integration of attachment, sex, and caregiving. In discussing these issues, they provide leads for future research and outline a more complete theory of romantic attachment.
\end{abstract}

During the past 12 years, attachment theory has become one of the major frameworks for the study of romantic relationships. It has generated hundreds of articles and several books, not to mention countless $\mathrm{PhD}$ and MA theses. An increasing number of conference papers and requests for reprints and information suggest that the study of romantic attachment will continue to attract interest for years to come. One reason for the popularity of the theory, we believe, is its provision of a unified framework for explaining the development, maintenance, and dissolution of close relationships while simultaneously offering a perspective on personality development, emotion regulation, and psychopathology. Moreover, the theory is intellectually rich, merging data and insights from disciplines as diverse as ethology, physiological psychology, control systems theory, developmental psychology, cognitive science, and psychoanalysis.

R. Chris Fraley and Phillip R. Shaver, Department of Psychology, University of California, Davis.

We thank Jim Cassandro, Lisa Feldman Barrett. Jennifer Frei, Paula Pietromonaco, Rick Robins, and Caroline Tancredy for their valuable comments on drafts of this article.

Correspondence concerning this article should be addressed to R. Chris Fraley, who is now at the Department of Psychology, University of Illinois at Chicago, 1007 West Harrison Street, Chicago, lllinois 60607-7137, or to Phillip R. Shaver, Department of Psychology, University of California, One Shields Avenue, Davis, California 95616-8686. Electronic mail may be sent to fraley@uic.edu or prshaver@ucdavis.edu.
The purpose of the present article is to revisit the theory of adult romantic attachment as it was originally formulated by Hazan and Shaver in the 1980s (Hazan \& Shaver, 1987; Shaver \& Hazan, 1988; Shaver, Hazan, \& Bradshaw, 1988) and summarize ways in which the theory has evolved over the last decade. As one might expect, some of the central tenets of the theory have received considerable empirical support, whereas others have been called into question or revised in light of new evidence or alternative theoretical proposals. Our goal is to highlight new developments, unanswered questions, and emerging controversies. In so doing, we hope to detail the ways in which the theory has changed over the last decade and provide an impetus for the empirical investigation of unresolved issues.

We begin with a brief discussion of the major tenets of romantic attachment theory as originally propounded by Hazan and Shaver (1987). We then describe some of the strengths of the theory, including ways in which it differs from previous theories, and highlight some of the novel research it has generated. Finally, we articulate what we consider to be important inadequacies of the original theory. To this end, we discuss tensions in the field, including controversies, debates, and unanswered questions. Our objective is not to review what has been learned about romantic attachment over the last 10 years (such reviews are available elsewhere; see Feeney, 1999; Feeney \& Noller, 1996; Shaver \& Clark, 1994) but to provide a 
useful guide to some of the issues that we believe need to be studied in the decade to come.

\section{Application of Attachment Theory to Adult Romantic Relationships}

Although attachment theory was originally designed to explain the emotional bond between infants and their caregivers, Bowlby (1979/ 1994) believed that attachment is an important component of human experience "from the cradle to the grave" (p. 129). He viewed attachment relationships as playing a powerful role in adults' emotional lives:

Many of the most intense emotions arise during the
formation, the maintenance, the disruption and the
renewal of attachment relationships. The formation of
a bond is described as falling in love, maintaining a
bond as loving someone, and losing a partmer as griev-
ing over someone. Similarly, threat of loss arouses
anxiety and actual loss gives rise to sorrow while each
of these situations is likely to arouse anger. The un-
challenged maintenance of a bond is experienced as a
source of security and the renewal of a bond as a
source of joy. Because such emotions are usually a
reflection of the state of a person's affectional bonds,
the psychology and psychopathology of emotion is
found to be in large part the psychology and psycho-
pathology of affectional bonds. (Bowlby, 1980, p. 40)

In the 1970 s and early 1980 s, several investigators began to use Bowlby's ideas as a framework for understanding the nature and etiology of adult loneliness and love. Some researchers had noticed that many lonely adults report troubled childhood relationships with parents and either distant or overly enmeshed relationships with romantic partners, suggesting that attachment history influences the frequency and form of adult loneliness (Rubenstein \& Shaver, 1982; Shaver \& Hazan, 1987; Weiss, 1973). Furthermore, social psychologists and anthropologists had observed considerable variability in the way people approach love relationships (ranging from intense preoccupation to active avoidance) and were developing individual-differences taxonomies to characterize this variability (e.g., Lee's "love styles" [Hendrick \& Hendrick, 1986; Lee, 1973, 1988] and Sternberg's components of love [Stemberg, 1986]). Despite these rich descriptions and taxonomies, there was no compelling theoretical framework within which to explain the normative phenomena of love or to organize and explain the observed individual differences (Hazan \& Shaver, 1994).
To address this need for a theory, Hazan and Shaver (1987) published an article in which they conceptualized romantic love, or pair bonding, as an attachment process, one that follows the same sequence of formative steps and results in the same kinds of individual differences as infant-parent attachment. Although the theory was originally spelled out in several extensive papers (Hazan \& Shaver, 1987; Shaver \& Hazan, 1988; Shaver et al., 1988), the central propositions can be summarized briefly.

1. The emotional and behavioral dynamics of infant-caregiver relationships and adult romantic relationships are governed by the same biological system. According to Bowlby, infant attachment behavior is regulated by an innate motivational system, the attachment behavioral system, "designed" by natural selection to promote safety and survival (Bowlby, 1969/1982; see also Insel, 2000). The internal dynamics of the attachment system are similar to those of a homeostatic control system in which a "set goal" is maintained by the constant monitoring of endogenous and exogenous signals and by continuous behavioral adjustment. In the case of the attachment system, the set goal is physical or psychological proximity to a caregiver. As illustrated in the top part of Figure 1, when a child perceives an attachment figure to be nearby and responsive, he or she feels safe, secure, and confident and behaves in a generally playful, exploration-oriented, and sociable manner. When the child perceives a threat to the relationship or to the self (e.g., illness, fear, or separation), however, he or she feels anxious or frightened and seeks the attention and support of the primary caregiver. Depending on the severity of the threat, these attachment behaviors may range from simple visual searching to intense emotional displays and vigorous activity (e.g., crying and insistent clinging). Attachment behavior is "terminated" by conditions indicative of safety, comfort, and security, such as reestablishing proximity to the caregiver.

Hazan and Shaver observed that adult romantic relationships are characterized by dynamics similar to these. For example, adults typically feel safer and more secure when their partner is nearby, accessible, and responsive. Under such circumstances, the partner may be used as a "secure base" from which to explore the environment (or engage in creative projects as part of leisure or work; Hazan \& Shaver, 1990). 

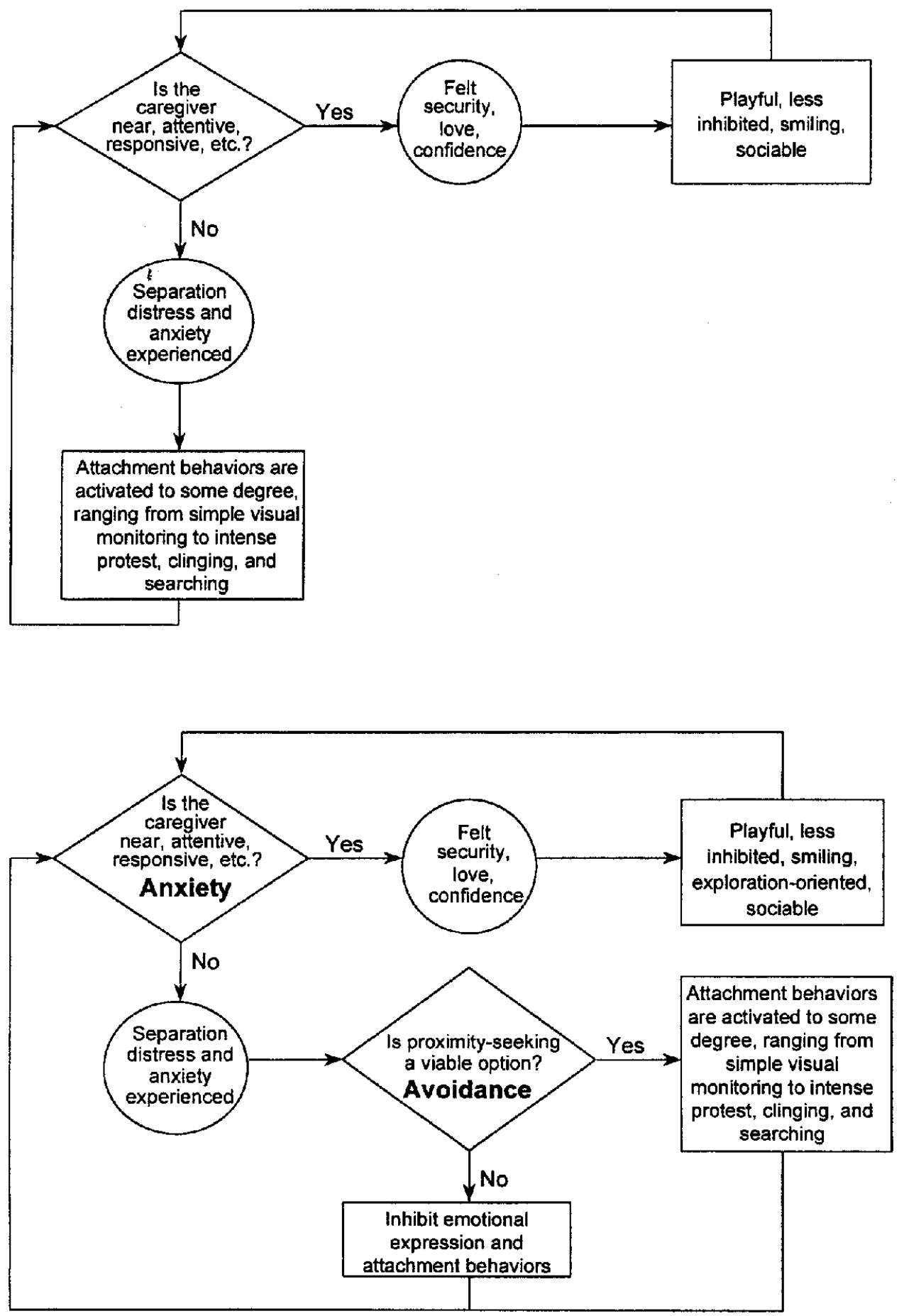

Figure 1. Top: Control-systems model of the rudimentary dynamics of the attachment system. Bottom: Modified version of the model. According to this model, the attachment system has two key components. The first is an appraisal component that detects and evaluates cues indicative of rejection or abandonment. The second is a behavioral selaction component responsible for organizing behavior and attention with respect to avoidance-oriented goals or proximity-seeking goals. 
When an individual is feeling distressed, sick, or threatened, the partner is used as a source of safety, comfort, and protection. Hazan and Shaver summarized other noteworthy parallels between infant--mother relationships and adult romantic relationships. For example, both kinds of relationships involve periods of ventral-ventral contact, "baby talk," cooing, and sharing of interesting "discoveries" and experiences. Thus, the emotions and behaviors that characterize romantic relationships and infant-parent relationships share similar activating and terminating conditions and appear to exhibit the same latent dynamics (Shaver et al., 1988).

2. The kinds of individual differences $o b$ served in infant-caregiver relationships are similar to the ones observed in romantic relationships. Specifically, Hazan and Shaver argued that the major patterns of attachment described by Ainsworth (secure, anxious-ambivalent, and anxious-avoidant) were conceptually similar to the "love styles" observed among adults by Lee and others (see Davis, Kirkpatrick, Levy, \& O'Hearn, 1994). Although Bowlby and Ainsworth had mentioned the role of attachment in adult romantic relationships, no one had actually attempted to assess and study, in the adult pair-bonding context, the kinds of individual differences described by Ainsworth and her colleagues (Ainsworth, Blehar, Waters, \& Wall, 1978).

When Hazan and Shaver (1987) began their work on romantic attachment, they adopted Ainsworth's three-category scheme as a framework for organizing individual differences in the way adults think, feel, and behave in romantic relationships. Specifically, they argued that three qualitatively distinct types of romantic, or pair-bond, attachment exist: secure, anxiousambivalent, and avoidant. In their initial studies, Hazan and Shaver $(1987,1990)$ developed brief multisentence descriptions of each of the three proposed attachment types ${ }^{1}$ as they were expected to be experienced by each kind of individual: "I am somewhat uncomfortable being close to others; I find it difficult to trust them completely, difficult to allow myself to depend on them. I am nervous when anyone gets too close, and often, others want me to be more intimate than I feel comfortable being" (avoidant). "I find it relatively easy to get close to others and am comfortable depending on them and having them depend on me. I don't worry about being abandoned or about someone getting too close to me" (secure). "I find that others are reluctant to get as close as I would like. I often worry that my partner doesn't really love me or won't want to stay with me. I want to get very close to my partner, and this sometimes scares people away" (anxious-ambivalent).

These descriptions were based on a speculative extrapolation of the three infant patterns summarized in the final chapter of the book by Ainsworth et al. (1978). Respondents were asked to think back across their history of romantic relationships and indicate which of the three descriptions best captured the way they generally experienced their romantic relationships. In their initial studies, Hazan and Shaver (1987) found that people's self-reported romantic attachment pattern was related to a number of theoretically relevant variables, including beliefs about love and relationships and recollections of early experiences with parents.

3. Individual differences in adult attachment behavior are reflections of the expectations and beliefs people have formed about themselves and their close relationships on the basis of their attachment histories; these "working models" are relatively stable and, as such, may be reflections of early caregiving experiences. The working models construct was rooted in the literature on infant attachment (for reviews, see Bretherton \& Munholland, 1999; Cassidy, 2000). According to attachment theory, the degree of security an infant experiences during the early months of life depends largely on exogenous signals, such as the proximate availability and responsiveness of primary caregivers. Over repeated interactions, however, children are theorized to develop a set of knowledge structures, or internal working models, that represent those interactions and contribute to the endogenous regulation of the attachment behavioral system. If significant others are generally warm, responsive, and consistently available, the child learns that others can be counted on when needed. Consequently, he or she is likely to explore the world confidently, initiate warm and sociable interactions with others, and find solace in the knowledge that the caregiver is potentially

\footnotetext{
'These types are sometimes referred to as attachment styles, attachment patterns, or attachment orientations in the literature on close relationships.
} 
available (Ainsworth et al., 1978). In short, the child has developed secure working models of attachment. If significant others are cold, rejecting, unpredictable, frightening, or insensitive, however, the child learns that others cannot be counted on for support and comfort, and this knowledge is embodied in insecure or anxious working models of attachment. The insecure child is likely to regulate his or her behavior accordingly, either by excessively demanding attention and care or by withdrawing from others and attempting to achieve a high degree of self-sufficiency (Main, 1990; for meta-analyses of the effects of maternal and paternal behavior on child security, see De Wolff \& van IJzendoorn, 1997; van IJzendoorn, 1995; van IJzendoorn \& De Wolff, 1997).

According to Hazan and Shaver (1987), working models of attachment continue to guide and shape close relationship behavior throughout life (for a review of the working model concept in adult attachment, see Pietromonaco \& Feldman Barrett, 2000). As people build new relationships, they rely partly on previous expectations about how others are likely to behave and feel toward them, and they use these models to interpret the goals or intentions of their partners. Working models are believed to be highly resistant to change because they are more likely to assimilate new relational information, even at the cost of distorting it, than accommodate to information that is at odds with existing expectations. In this respect, the theory explains continuity in the way people relate to others across different relationships. Moreover, the theory suggests that early caregiving experiences influence, at least in part, how people behave in their adult romantic relationships. As such, the theory provides a way to preserve an early psychoanalytic insight about adult relational patterns without introducing controversial psychoanalytic mechanisms, such as regression or fixation.

4. Romantic love, as commonly conceived, involves the interplay of attachment, caregiving, and sex. Although romantic love is partly an attachment phenomenon, it involves additional behavioral systems, caregiving and sex, that are empirically intertwined with attachment but theoretically separable. In infancy, attachment behavior is adaptive only if someone (i.e., a parent) is available to provide protection and support. Typically, a parent provides protection and care to the infant. In adult relationships, however, these roles (attachment and caregiving) are more difficult to separate. Either partner can be characterized at one time or another as stressed, threatened, or helpless and hence as needing responsive, supportive care from the other. Similarly, either partner can be characterized at times as being more helpful, empathic, or protective. In a long-term relationship, the attachment and caregiving roles are frequently interchanged.

Sexuality is also of major importance in understanding romantic love. Although there are good reasons to consider attachment and sexual behavior as regulated by different systems, it is difficult to deny that the two systems mutually influence each other. For example, a person may forgo his or her sexual desires or needs when feeling distressed or anxious about the whereabouts of a long-term mate. Similarly, a person may adopt sexual strategies (e.g., short-term mating strategies) that serve to inhibit the development of deep emotional attachments (i.e., serve the function of intimacy avoidance and dependency avoidance).

In sum, from Hazan and Shaver's perspective, romantic love can be understood in terms of the mutual functioning of three behavioral systems: attachment, caregiving, and sex. Although each system serves a different function and has a different developmental trajectory, the three are likely to be organized within a given individual in a way that partly reflects experiences in attachment relationships.

\section{Strengths of an Attachment-Theoretical Approach}

One strength of attachment theory is its placement of intimate relationships in an ethological framework. An ethological approach broadens the nature of the questions asked about a phenomenon, thereby making the answers more comprehensive (Hinde, 1982). Many nonethological researchers are trained to ask highly circumscribed questions about a behavior pattern, such as "What are the causal mechanisms underlying this pattern?" or "How does this pattern develop?" Ethologists recognize at least two other questions: questions concerning function (e.g., "What is this behavior for, and how does it contribute to survival or reproduction?") and evolution (e.g., "How did it evolve?"). 
Taken together, these four questions-causation, development, function, and evolutioncharacterize the ethological approach to behavior (Tinbergen, 1963). ${ }^{2}$

As an illustration of the value of an ethological approach to relationships, consider the example of relationship dissolution due to loss or separation. Separated or bereaved individuals continue to yearn for and pine for their separated partners long after separation, sometimes for years. They are particularly sensitive to perceptual cues related to their partner (e.g., readily mistaking a passerby for their lost partner) and have a difficult time finding someone who can fill the gap left in their lives by the absence of their partner (see Parkes \& Weiss, 1983). The empirical literature on separation and loss has focused primarily on the various predictors of such postdissolution distress. Doing so has led to a number of interesting discoveries. For example, highly neurotic people tend to experience more distress after a loss than less neurotic people (Vachon et al., 1982). Social support sometimes buffers the negative effects of loss (Stylianos \& Vachon, 1993). However, in trying to account for variation in postseparation distress, this line of inquiry has addressed questions about causal mechanisms only. An ethological approach, such as attachment theory, would also ask the following questions: Why do separated partners experience anxiety? Do searching and vigilance serve a function that might facilitate, or once have facilitated, survival or reproductive fitness? How do these behavioral and emotional reactions develop? How early in life can they be observed? How did these behaviors evolve? Are they present in other species, and do they serve similar functions in those species?

A second advantage of the attachment-theoretical perspective on intimate relationships is that, in addition to focusing on normative aspects of relational processes (Hazan \& Shaver, 1994), it draws attention to variability in the way people experience and behave in relationships. In fact, it is the individual-differences component of the theory that has attracted the most research attention. Hazan and Shaver's three-category model of individual differences has been influential for at least three reasons. First, it provides a framework broad enough to account for the kinds of variability detailed by astute observers of human relational behavior (e.g., Lee, 1973; Sternberg, 1986), including the cool aloofness exhibited by some people and the intense preoccupation with relationships exhibited by others. Second, the developmental assumptions of the model allow variation in infant and romantic attachments to be understood within the same theoretical framework. Third, the model nicely incorporates the major assumptions of social psychology and personality psychology. That is, it postulates a set of mechanisms (i.e., working models) that contribute to individual stability while recognizing the powerful influence of environmental factors on attachment behavior.

Attachment theory's focus on individual differences has inspired many interesting studies that, we believe, would not have been generated by alternative theoretical approaches to close relationships. For example, researchers have examined the influence of working models on the inferences people make about their partner's intentions (Collins, 1996); the interplay of distress and working models as determinants of attachment and caregiving behavior (Fraley \& Shaver, 1998; Simpson, Rholes, \& Nelligan, 1992); the role of working models in partner preferences (Chappell \& Davis, 1998; Frazier, Byer, Fischer, Wright, \& DeBord, 1996; Pietromonaco \& Carnelley, 1994), relationship stability (Kirkpatrick \& Davis, 1994; Kirkpatrick \& Hazan, 1994), and relationship dissolution (Feeney \& Noller, 1992; Pistole, 1995; Simpson, 1990); and the psychodynamic organization and functioning of working models (Bartholomew, 1990; Fraley, Davis, \& Shaver, 1998; Fraley \& Shaver, 1997; Mikulincer, 1998; Mikulincer, Florian, \& Tolmacz, 1990; Mikulincer \& Orbach, 1995).

\section{Theoretical Developments, Emerging Controversies, and Unanswered Questions}

Despite the strengths of the attachment-theoretical perspective, its 1980 s formulation suffers from a number of limitations. For example, the theory contained an implicit assumption that all

\footnotetext{
${ }^{2}$ Ethology is sometimes narrowly defined as the study of animals in their natural environments. Although it is true that some ethologists study animals in their natural environments, the field is better characterized by its focus on the biological study of behavior, wherein biology is conceptualized more broadly than physiology.
} 
romantic relationships are attachment relationships, and it therefore failed to provide a means of separating attachment from nonattachment relationships. It also failed to provide a clear account of the evolution and function of attachment in romantic relationships. In addition, since 1987 several theoretical and empirical developments have challenged parts of Hazan and Shaver's formulation of romantic, or pair-bond, attachment theory. Our objective in this section is to make these controversies and unanswered questions explicit and suggest how they might be resolved.

\section{What Is an Attachment Relationship?}

In the literature on infant-parent attachment, it is generally assumed that all children are attached to their primary caregivers (Cassidy, 1999). Individual differences in attachment are thought to reflect differences in the quality of the relationship, not differences in the degree of attachment or the presence or absence of attachment per se. In the context of adult relationships, however, it is not necessarily the case that romantic partners are attached to each other. Although it is frequently assumed in the literature on romantic attachment that relationships beyond some arbitrary length are attachment relationships, this assumption is rarely tested. It is critical to do so because there are good reasons to believe that the kinds of processes studied by attachment researchers are a function not only of attachment style but also of whether the relationship serves attachment-related functions for the individuals involved (see Fraley \& Davis, 1997; Fraley \& Shaver, 1999). Also, in exploring the role of attachment in other kinds of relationships (e.g., friendships, sibling relationships, attachments to teachers or nurses, and spiritual relationships), it is necessary to have a theoretically defensible way to establish or qualify the nature of the bond under investigation.

Attachment theorists have proposed a variety of features that distinguish attachment relationships from other kinds of relationships (Ainsworth, 1982, 1991; Hazan \& Zeifman, 1994; Weiss, 1982, 1991). Threc functions or features reappear in various taxonomies. First, an attachment bond is marked by the tendency for an individual to remain in close contact with the attachment figure. That is, the attachment figure is used as a target of proximity maintenance, and separations, when they occur, are temporary and typically met with some degree of distress or protest. Second, an attachment figure is used as a safe haven during times of illness, danger, or threat. In other words, the attached individual uses the attachment figure as a haven of safety, protection, and support. Third, an attachment figure is relied on as a secure base for exploration. The presence of the attachment figure promotes feelings of security and confidence, thereby facilitating uninhibited and undistracted exploration.

Researchers have used these features to differentiate attachment from nonattachment relationships in adulthood. Hazan and her colleagues (Hazan, Hutt, Sturgeon, \& Bricker, 1991) created self-report and interview methods for identifying a person's attachment figures. These methods instruct people to nominate one or more individuals whom they use as (a) a target for proximity maintenance, (b) a safe haven, and (c) a secure base. According to Hazan et al.'s cross-sectional research, children primarily nominate their parents for these roles or functions, but adolescents and adults tend to nominate their peers (close friends or romantic partners). According to Hazan et al.'s model, the three functions are serially transferred from one attachment figure, or set of attachment figures, to another, with proximity maintenance being transferred first, followed by safe haven and, finally, secure base. This pattern of transfer corresponds to the stages of attachment development that Ainsworth (1972; elaborating on Bowlby, 1969/1982, pp. 265-268) called "preattachment," "attachment in the making," and "clear-cut attachment." The best candidate for a true attachment relationship is one in which all three functions are present.

Fraley and Davis (1997) modified the instruments used by Hazan et al. to study the extent to which young adults had transferred each of the attachment-related functions from parents to romantic partners. In a sample of young adults, Fraley and Davis found that people who had transferred more of these functions to their peers (friends or romantic partners) had peer relationships characterized by more caring, trust, and intimacy. Also, consistent with Hazan et al.'s findings, romantic attachments took approximately 2 years, on average, to develop, and secure individuals were more likely than 
insecure individuals to use their romantic partners as attachment figures.

Although these studies are reasonable initial attempts to differentiate attachment relationships from other kinds of emotional relationships in adulthood, the measures used are limited in a number of respects. First, as Trinke and Bartholomew (1997) observed, some individuals are inclined to use their partners as a safe haven during times of distress but do not necessarily act on this inclination. To the extent that this is the case, asking people whom they actually use as a safe haven, for example, may lead to inaccurate inferences about their attachment dynamics. In an attempt to deal with this problem, Trinke and Bartholomew developed a self-report instrument that asks people whom they would like to use, as well as whom they actually do use, as a safe haven and secure base.

A second potential concern with existing research on this topic is that the instruments used by Hazan et al. (1991), Fraley and Davis (1997), and Trinke and Bartholomew (1997) led to the conclusion that secure individuals are more likely to use their relationship partners as attachment figures. Although this finding is likely to reflect something real about the nature of attachment relationships (i.e., people may be more confident in exploring possible peer attachments if they are securely attached to their parents), it may also reveal a problem in defining attachment relationships with respect to their beneficial functions (e.g., providing safety and security). Consider how the results might differ if attachment were assessed in terms of "negative" indexes. According to Weiss (1991), the best marker of an attachment may be the presence of prolonged distress and disruption following the end of the relationship. ${ }^{3}$ If intensity or duration of disruption were used as an index of attachment, however, anxious individuals might appear more attached to their partners than secure individuals. In fact, research does indicate that highly anxious people are more likely to experience separation distress after temporary separations (Fraley \& Shaver, 1998) and losses (Feeney \& Noller, 1992; van Doorn, Kasl, Beery, Jacobs, \& Prigerson, 1998). This misleading implication was one of Ainsworth's reasons for downplaying the notion of attachment "strength." An important objective for future research is to uncover theoretically defensible indicators of attachment devel- opment that are not confounded with security or insecurity.

In addition to delineating and assessing features that differentiate attachment from nonattachment relationships, there are a number of outstanding questions that need to be answered with respect to attachment formation and transfer in adulthood. First, how do people with insecure attachments negotiate the transfer of attachment-related functions to new relationships? It seems as if insecure individuals might be more likely than secure individuals to find an alternative partner attractive, if that partner appeared to solve problems experienced by the insecure person in a current relationship; however, the insecure person might also carry doubts, worries, and negative expectations into the new (real or imagined) relationship, thus making it unlikely that the new relationship could easily solve ongoing problems. Second, how are attachment hierarchies reorganized after the dissolution of a relationship (e.g., divorce, separation, or death)? Research on bereavement shows that individuals frequently find ways to continue their bonds with deceased spouses or parents (Klass, Silverman, \& Nickman, 1996), indicating that deceased attachment figures can retain a privileged position in a person's attachment hierarchy. Little is known about how this reorganization works after divorce or the breakup of a premarital romantic relationship. Third, how do defensive processes influence the development of attachment relationships? Fraley and Davis (1997) found that dismissing individuals were less likely to have formed attachment relationships with their partners, even when relationship length was controlled. Thus, part of avoidant individuals' characteristic defensive strategy may be to inhibit the formation of attachment in new relationships (Fraley et al., 1998).

\section{Evolution and Function of Adult Attachment}

Another undeveloped aspect of the original theory has to do with the function and evolution of attachment in adult romantic relationships

\footnotetext{
${ }^{3}$ For obvious reasons, the amount of distress or disruption following relationship dissolution cannot be used to study the presence of attachment in intact relationships.
} 
(but see Hazan \& Diamond, 2000). According to romantic attachment theory, many of the behaviors and dynamics that characterize romantic relationships are driven by the same motivational system (the attachment behavioral system) that regulates attachment behavior in infancy. The patterns of behavior observed in infancy and adulthood are considered behavioral homologies; that is, they are thought to be rooted in a common behavioral system activated and terminated by the same kinds of conditions and serving the same goals. Shaver et al. (1988) speculated that the attachment system has been "co-opted" by natural selection to facilitate bonding between mates, which may, in turn, facilitate the survival of offspring. However, the ways in which pair bonding contributes to fitness were left unspecified.

Variants of this hypothesis have been offered in the biological literature on monogamy (e.g., see Gubernick, 1994, for a summary of several hypotheses concerning the evolution of monogamy) ${ }^{4}$ According to our reading of this literature, monogamy or pair bonding is adaptive in at least three ways. First, it appears to solve, or help to solve, the problem of paternity certainty. Because ovulation is concealed in women, men run the risk of investing in offspring that are not theirs. One way to increase paternity certainty is to maintain proximity to one's mate. Comparative research on more than 60 anthropoid primate taxa by Sillen-Tullberg and Møller (1993) indicates that monogamous mating systems are more common in taxa with concealed ovulation than in taxa with visible signs of ovulation. According to these authors' phylogenetic analyses, the lack of ovulatory signals is likely to have preceded the development of monogamy during evolutionary history, suggesting that concealed ovulation may have created confusion on the part of males concerning paternal certainty, thereby indirectly facilitating pair bonding.

Pair bonding also appears to improve fitness by providing additional protection for immature offspring. There is some evidence that offspring are more likely to survive to reproductive age if they are reared in families in which mother and father are pair bonded. In humans, for example, Daly and Wilson have shown that children are at much greater risk of being murdered by stepfathers than by their biological fathers (Daly \& Wilson, 1988). Also, as noted by Wilson and
Daly (1994), unpaired women may at times abdicate care of their offspring because of an inability to raise the child alone. Having a child without a partner may compromise a woman's prospects with future mates, and, if she does acquire a mate, he is likely to discriminate against her child (Wilson \& Daly, 1994; see also Hrdy, 1992). There is also evidence that the presence of an invested primate male deters potential threats by other members of the group (van Schaik \& Dunbar, 1990).

A third reason why pair bonding may be adaptive is that, given the extended period of immaturity characterizing human young, human infants are especially vulnerable and dependent (Bjorklund, 1997), taking almost twice as long to reach sexual maturity as chimpanzees, our closest biological relatives (Poirier \& Smith, 1974). As Bjorklund (1997) argued:

\begin{abstract}
Pair bonding and some division of labor ... may be a necessary adaptation to the pressures presented by the slow growth of offspring, increasing the likelihood that children would survive to sexual maturity. The long period of dependency also means that the man's genetic success could not be measured just by how many women he inseminated or by how many children he sired. His inclusive fitness would depend on how many of his offspring reached sexual maturity.... To increase the odds of this happening, his help in the rcaring of his children would be needed. (p. 156)
\end{abstract}

These observations are consistent with the hypothesis that attachment between mates evolved to help ensure paternity certainty and the successful rearing of offspring to reproductive age. It is noteworthy that the leading predictors of divorce in humans include infidelity and infertility (Buss, 1994). This further suggests that the pair bond (e.g., romantic attachment) developed to aid in the rearing of offspring and that, when paternity certainty or mating prospects are called into question, pair bonds are more likely to dissolve.

This analysis has its limitations, however. First, monogamy or pair bonding characterizes

\footnotetext{
${ }^{4}$ As noted by Kleiman (1977) and Gubernick (1994), monogamy is commonly misconstrued as referring to mating exclusivity. However, animals classified as monogamous rarely exhibit clear-cut evidence of mating exclusivity. The term monogamous is generally used to refer to animals in close proximity to one another, with clear mating preferences for one another, and the presence of a strong emotional bond. This arrangement increases sexual exclusivity but does not guarantee it.
} 
fewer than $3 \%$ of mammalian mating systems (Kleiman, 1977). Thus, romantic attachment is relatively rare. ${ }^{5}$ If it is an adaptive solution to the problems of paternity certainty and the successful rearing of offspring, then it is a solution that most mammals did not adopt. Second, even among species exhibiting evidence of romantic pair bonds, there is considerable diversity in the way those bonds manifest themselves. For example, in titi monkeys (Callicebus moloch), adult partners form intense emotional attachments, but they are not particularly emotionally invested in their offspring. When given a preference test between mate and infant, both parents prefer their mate (Mendoza \& Mason, 1986). Infants survive largely as a result of their own efforts to ride on the shoulders of their tolerant, but perhaps not emotionally bonded, fathers. Mothers sometimes push their infants away as soon as a bout of nursing is completed.

These kinds of maternal caregiving behaviors stand in stark contrast to those of another monogamous primate species, Lemur mongoz, whose female members are highly protective of their offspring. These cross-species differences in infant-parent and adult-adult attachments may have occurred because of different constellations of selection pressures. In fact, recent phylogenetic evidence indicates that monogamy may have evolved independently among many mammalian species (Komers \& Brotherton, 1997). Thus, even though species as diverse as humans, titi monkeys, prairie voles, and the California mouse exhibit signs of pair bonding, it is not because they share a common ancestor. In fact, the mating system of one of our closest genetic relatives, the common chimpanzee ( $\mathrm{Pan}$ troglodytes), differs in a number of ways from our own. Chimpanzee females mate with more than one male, there are clear signs of ovulation (sexual swellings), and males play little direct role in the rearing of their offspring. In sum, the evolution of romantic attachment might require different explanations for different species.

In the case of our own species, it is worth considering that attachment in human adults may be a by-product of our prolonged neotenous state. As mentioned already, humans are unique relative to other primates in retaining juvenile characteristics for an extended period. Relative to the brains of other animals, the human brain takes a long time to develop, humans remain relatively hairless, our teeth erupt at a late age, and our sexual maturation is delayed (Montagu, 1989). According to some writers, changes in the timing of developmental processes represent one of the major forces of evolutionary change (deBeer, 1958). Perhaps attachment, like other infantile traits, is prolonged into early adolescence and adulthood because of the relative retardation of general maturational processes in humans. If so, then the attachment system will not become dormant at some point during development, as it appears to do in adults of nonmonogamous species. Instead, the system will continue to be sensitive to certain cues and signals and readily activated in contexts that resemble the infant-parent relationship (e.g., caring, contingent, or physically intimate interactions) or elicit similar feelings or behaviors.

How can one get a better grip on the evolutionary issues surrounding adult attachment? We believe that comparative and phylogenetic research would be extremely valuable. Such research could test the hypothesis that neoteny is correlated with monogamy. This could be tested either between species (e.g., Do age of sexual maturation and kind of mating system covary?) or within species (e.g., Are individuals within a species who take longer to mature more likely to form or seek long-term or monogamous relationships?). Another hypothesis that could be tested in comparative research is that the presence of attachment in infancy is a necessary condition for attachment in adults. If the infantile attachment system is truly co-opted for new functions in adulthood, then there should be few species that exhibit signs of romantic attachment that do not also exhibit infant-parent attachment. All of the species with which we are familiar that can be characterized as forming romantic, or pair-bond, attachments can also be characterized as exhibiting attachment in infancy.

\footnotetext{
${ }^{5}$ If the period of immaturity in other mammalian young is not as long as in humans, then evidence of pair bonding might be hard to find. It is only necessary that the pair bond last long enough for the children to reach reproductive maturity. If that happens in, say, a year, then the brief pair bond might not be recognized as such by observers.
} 
To our knowledge, however, this issue has never been examined systematically. ${ }^{6}$

\section{Individual Differences in the Organization of the Attachment System}

Extensions of the original framework. Hazan and Shaver's (1987) three-category model of individual differences was designed to capture adult analogues of the three attachment types described by Ainsworth and her colleagues. Shortly after Hazan and Shaver's initial studies, however, several concerns were raised about the three-category model. Bartholomew (1990; Bartholomew \& Horowitz, 1991), for example, noticed that the avoidant pattern described by Hazan and Shaver conflated two theoretically distinct forms of avoidance, which she called fearful-avoidance and dismissingavoidance. Bartholomew argued that some individuals - those who are fearfully avoidantadopt an avoidant orientation toward attachment relationships to prevent being hurt or rejected by partners. Dismissing individuals, she suggested, adopt an avoidant orientation as a way to maintain a defensive sense of selfreliance and independence.

Bartholomew thus proposed a four-category model of individual differences in adult attachment. She retained the secure and anxious-ambivalent (or preoccupied) classifications from the three-category model but divided the avoidant category into two categories: fearfulavoidance and dismissing-avoidance. She also argued that these four types could be placed within a two-dimensional space defined by the valence of people's representational models of the self and others. Specifically, secure individuals were characterized as holding positive representations of the self (e.g., viewing themselves as worthy and lovable) and of others (e.g., viewing them as responsive and attentive). Within this framework, each of the four attachment types results from a unique combination of positive and negative models of the self and others.

A second limitation of the three-category model was uncovered by M. B. Levy and Davis (1988). Working with continuous ratings of the three categorical descriptions, Levy and Davis found that the ratings of the secure and avoidant patterns were much more negatively correlated than the ratings of the secure and anxious- ambivalent types, suggesting a two-dimensional structure. This finding raised questions about the validity of the categorical model of attachment. Subsequently, a "types versus dimensions" debate began (Collins \& Read, 1990; Fraley \& Waller, 1998; Griffin \& Bartholomew, 1994a). Some researchers argued in favor of a typological approach because the types provided organized, functional wholes from which hypotheses about dynamics could be derived (e.g., Brennan \& Shaver, 1995; Brennan, Shaver, \& Tobey, 1991); others argued in favor of dimensions for psychometric (Fraley \& Waller, 1998; Simpson, 1990) or conceptual (Griffin \& Bartholomew, 1994b) reasons.

Fraley and Waller (1998) pointed out that many of the methods used by researchers to answer the types versus dimensions question (e.g., cluster analysis) were not well suited to the task. Instead, these authors used taxometric techniques developed by Meehl and his colleagues (Meehl, 1995). Unlike other techniques, taxometric methods are able to distinguish latent types from latent dimensions. Fraley and Waller's analyses indicated that categorical models are inappropriate for studying variation in romantic attachment. The data were more consistent with a dimensional model of individual differences.

To help identify the optimal dimensional system for organizing individual differences in romantic attachment, Brennan, Clark, and Shaver (1998) scoured the literature and identified a nearly exhaustive set of models and measures. They administered more than 320 self-report items from diverse inventories to a large sample of respondents to uncover similarities and differences among the measures. Their analyses revealed that individual differences in romantic attachment can be organized within a two-dimensional space. One of the dimensions, which Brennan and her colleagues called anxiety, corresponds to anxiety and vigilance concerning rejection and abandonment. The other dimension, which Brennan and her colleagues called avoidance, corresponds to discomfort with

\footnotetext{
${ }^{6}$ For further discussion of the evolutionary roots of romantic attachment, see Fisher (1998), Miller and Fishkin (1997), and Zeifman and Hazan (1997). Kirkpatrick (1998) proposed an alternative explanation for romantic bonds that does not require attachment-based mechanisms, but his analysis has been challenged by Hazan and Zeifman (1999).
} 
closeness and dependency or a reluctance to be intimate with others. Empirically, these dimensions map onto the model of self and model of other dimensions, respectively, in Bartholomew's theoretical model. (See Fraley, Waller, \& Brennan, 2000 , for an item response theory analysis of measures of these dimensions.)

Alternative interpretations of the two dimensions. Although two major dimensions seem to underlie individual differences in adult romantic attachment, there are at least two different ways of thinking about the dimensions. Some researchers favor the "model of self and model of others" interpretation (e.g., Carnelley, Pietromonaco, \& Jaffe, 1994; Klohnen \& John, 1998), whereas others favor an emotional and behavioral regulation interpretation (Fraley \& Shaver, 1998; Shaver et al., 1988). Within Bartholomew's (1990; Griffin \& Bartholomew, 1994b) framework, individual differences are conceptualized as differences in the models people maintain of themselves and others. Accordingly, many researchers have attempted to specify the actual beliefs that people with different attachment orientations hold (e.g., Baldwin, Fehr, Keedian, Seidel, \& Thomson, 1993; Collins, 1996; Klohnen \& John, 1998).

In our opinion, there are at least three limitations to the model of self and model of others framework. First, the manifest content of the items typically used to assess these dimensions is more consistent with a conceptualization that focuses on sensitivity to rejection and comfort with depending on others. Second, the model of self and model of others conceptualization requires that preoccupied individuals have a positive model of others, a model of others as available, responsive, attentive, and so forth. This characterization is at odds with the empirical literature, which suggests that highly preoccupied individuals are often angry, jealous, combative, and prone to feel that partners are insensitive to their needs (e.g., Collins, 1996; Simpson, Rholes, \& Phillips, 1996). Third, attachment behavior is common to many species that arguably do not have particularly sophisticated representational models of themselves (see Robins, Norem, \& Cheek, 1999, for a discussion of self-representation in nonhuman primates). In fact, research indicates that human infants do not have the capacity to reflect on themselves and the minds of others in complex ways during the first years of life (Astington,
Harris, \& Olson, 1988; Yirmiya, Erel, Shaked, \& Solomonica-Levi, 1998). To the extent that this is true, framing individual differences in adult attachment in terms of representations of the self and others may require models of individual differences for adults and human or nonhuman infants based on different assumptions.

We believe that, if the working models construct is to be useful, working models must be conceptualized with respect to the ways in which they influence the operation of the attachment system. Recently we have been attempting to reframe individual differences in attachment as arising from variation in the organization of the attachment behavioral system rather than from representations of the self and others per se (e.g., Fraley \& Shaver, 1998). From this perspective, the two dimensions common to self-report instruments of adult attachment can be conceptualized as reflecting variability in the functioning of two fundamental subsystems or components of the attachment behavioral system. The bottom part of Figure 1 displays a control-systems representation of the dynamics of these subsystems based on theoretical discussions by Fraley and Shaver (1998); Kobak, Cole, Ferenz-Gillies, Fleming, and Gamble, (1993); Lazarus and Folkman (1984); and Shaver et al. (1988). One component of the system involves monitoring and appraising events for their relevance to attachment-related goals, such as the attachment figure's physical or psychological proximity, availability, and responsiveness. When the system detects a discrepancy between the current set goal for sensitivity and proximity and the perceived behavior of the attachment figure, the individual feels anxious and becomes increasingly vigilant to attachment-related cues. Variation in people's threshold for detecting threats to security or cues of rejection corresponds to individual differences in what Brennan, Clark, and Shaver (1998) called anxiety. The second component is responsible for regulation of attachment behavior with respect to attachment-related goals. For example, to regulate attachment-related anxiety, people can orient their behavior toward the attachment figure (i.e., seeking contact or support) or withdraw and attempt to handle the threat alone. Variation in this behavioral orientation component is responsible for individual differences on Brennan et al.'s avoidance di- 
mension (for a complementary view, see Pietromonaco \& Feldman Barrett, 2000).

Several additional features of the model deserve elaboration. First, the two components are conceptualized as operating in parallel. Thus, although avoidance strategies, such as gaze aversion, may serve to reduce or deactivate unpleasant feelings after a threat has been detected, the activation of these strategies is not contingent on the actual perception of a threat or the experience of anxiety. Avoidant strategies may operate preemptively, by minimizing the likelihood of threatening events (e.g., behaving in a submissive manner or failing to reveal one's vulnerabilities; see Bowlby's, 1980, discussion of defensive exclusion for a more detailed analysis of the role of defenses in avoidant attachment). Nonetheless, the activity of each subsystem may feed back into the other, producing coordinated dynamics. For example, Fraley and Shaver (1997) found that highly preoccupied individuals (i.e., people high in anxiety and oriented toward proximity seeking) became more anxious over time when they were attempting to suppress or deactivate abandonment-related thoughts.

Second, the intensity of behaviors exhibited (e.g., simple visual searching vs. vigorous protest behaviors) is a function of the degree of anxiety the individual is experiencing at any particular moment. The motivational orientation of regulatory strategies (i.e., whether they are directed toward contact maintenance or contact avoidance), however, is controlled by the "avoidance" component of the system, regardless of behavioral intensity.

Third, although an individual's behavior may be modulated by conscious processes, the appraisal or monitoring components of the system can operate automatically, without conscious awareness or deliberation. Evidence for this possibility comes from case studies of bereavement (Parkes \& Weiss, 1983). Grieving individuals continue to feel anxious and compelled to search for their lost partner despite knowing that attempts to regain contact with this person may be futile. Although certain aspects of the system are theorized to be beyond an individual's conscious control, the organization of the system may nonetheless be reflected in a person's conscious experience. In other words, people may be aware of how much or how frequently they worry about their partner's whereabouts, even if they have little control over the systems that monitor proximity to the attachment figure. Similarly, people may be aware of the kinds of behavioral strategies they typically use to regulate attachment behavior based on a history of interacting with attachment figures.

Fourth, Bartholomew's four theoretical "types" can be reconceptualized as linear combinations of anxiety and avoidance. For example, security and dismissing-avoidance are characteristic of people who have high thresholds for detecting cues of rejection. Preoccupation and fearful-avoidance are characteristic of individuals with low thresholds for detecting such cues, making concerns about love-worthiness and rejection particularly salient. Security and preoccupation characterize people who wish to be close to and intimate with their partners. Dismissing-avoidance and fearful-avoidance characterize people who try to deny the importance of close relationships or force themselves not to become vulnerable to them.

One advantage of framing individual differences in terms of the organization of the attachment system's dynamics rather than in terms of working models of the self and others is that doing so allows individual differences in infancy and adulthood to be placed within the same framework. The left-hand panel of Figure 2, an adaptation of Figure 10 from Ainsworth et al. (1978), presents the results of a discriminant analysis involving 105 infants who had been categorized and scored by coders on Ainsworth's infant behavior scales (e.g., crying, contact maintenance, exploratory behavior, resistance, and avoidance). Ainsworth and her colleagues found two linear combinations that discriminated well between the three infant categories. One function distinguished anxiousambivalent from secure and avoidant infants, thereby reflecting variability in anxiety about separation and abandonment. The other function distinguished avoidant from secure and anxious-ambivalent infants, thereby reflecting variability in the use of avoidant versus contactseeking strategies (see Brennan, Clark, \& Shaver, 1998, for a detailed discussion of these findings). These two dimensions can be viewed as reflecting variation in the organization of the two components of the attachment system modeled in the bottom part of Figure 1, a conceptualization that fits both children's and adults' attachment behavior. In other words, adult at- 


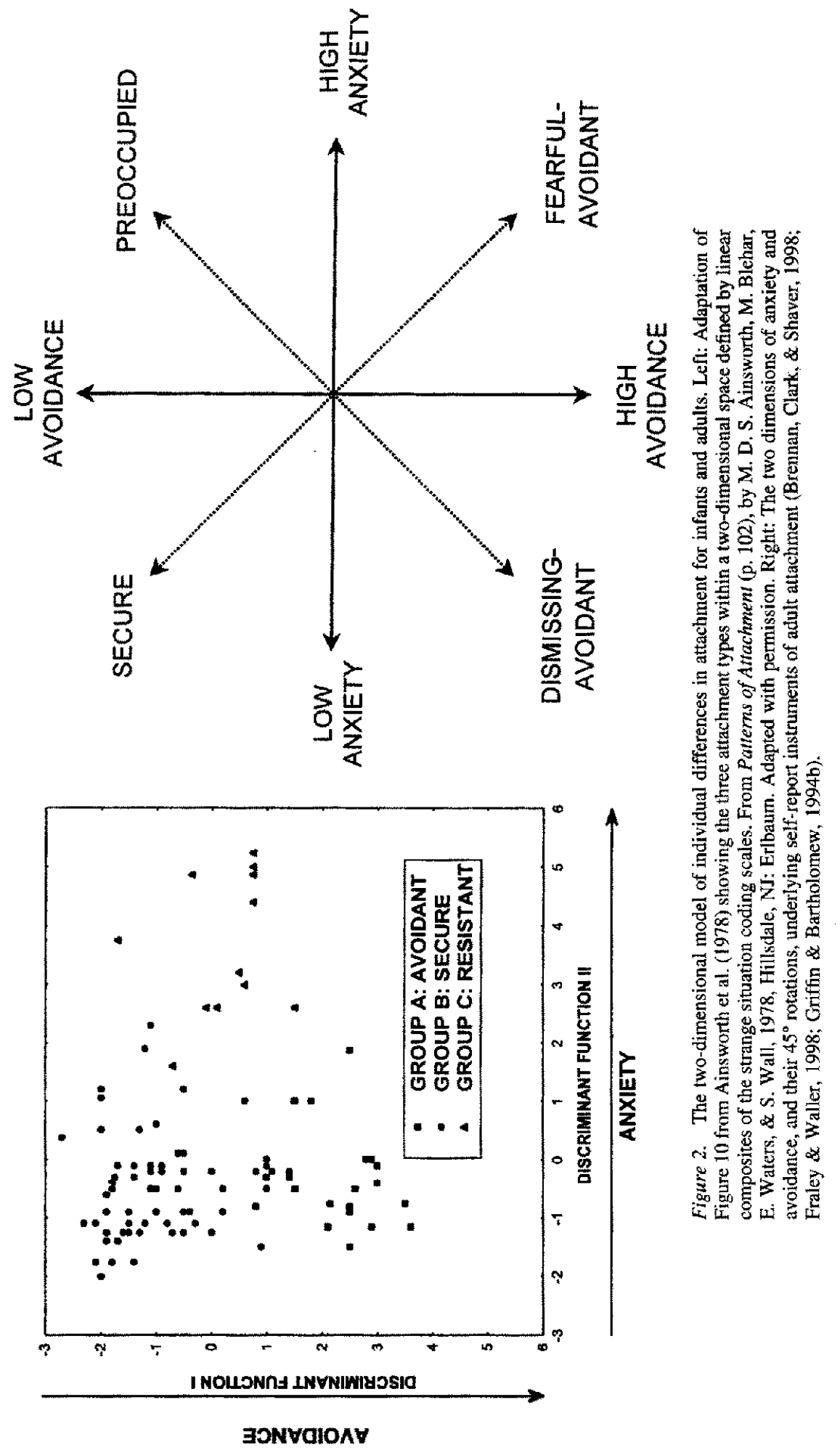


tachment patterns (as captured by self-report measures) and infant attachment patterns (as captured by the strange situation procedure) can be viewed as having the same latent structure and dynamics.

A second advantage of our theoretical framework is that when the two dimensions are viewed with respect to the functional organization of the attachment system, further specification of the working models (i.e., the expectations, concerns, appraisals, and emotional processes that underlie adult romantic attachment experiences and behavior) is not limited to positive and negative beliefs about the self and others. ${ }^{7}$ The structure and function of working models (whether conscious or unconscious) are likely to vary in a number of ways. For example, a dismissing individual may believe that relationships are not worth much time or effort, that he or she is capable of succeeding without the help of others, and that he or she should not worry about being rejected by partners. Although these beliefs can be characterized along many dimensions (degree of investment in others, self-sufficiency, and fear of abandonment), it is likely that they intersect with a behavioral system consisting of only a few parts. In other words, these multifaceted representations may funnel into a behavioral orientation characterized by a single goal: intimacy avoidance. Thus, a two-dimensional model may be sufficient for representing variation in fundamental attachment processes, even if people's beliefs or representations vary in many ways.

Another advantage of focusing on two functionally distinct components of the attachment system is that a more refined set of questions concerning attachment processes and close relationships can potentially be investigated. For example, it is possible that the two components of the system manifest themselves differently in social interactions. In a naturalistic study of separating couples, Fraley and Shaver (1998) found that variation in anxiety was related to self-reported separation anxiety among women, but only variation in avoidance was related to the actual behavioral strategies these women used. In other words, although highly anxious women felt anxious about the impending separation, only those who were comfortable with intimacy (Bartholomew's preoccupied individuals) sought contact and comfort from their partners. Another implication of the model is that variation in anxiety is sensitive to changes in relationship functioning (such as frequency of separation or responsiveness of the caregiver), whereas variation in avoidance is less affected by relational changes. In fact, in longitudinal and cross-sectional studies of individuals and relationships, attachment-related anxiety has been shown to decrease over time, but avoidance has not (Klohnen \& John, 1998; Mickelson, Kessler, \& Shaver, 1997). Thus, it is possible that sensitivity and vigilance to cues of rejection and abandonment decrease as relationships persist, although people continue to use their characteristic strategies for regulating anxiety and intimacy. Thinking along these lines, we hypothesize that anxiety-reducing drugs affect the intensity but not the avoidant-nonavoidant orientation of attachment behaviors.

\section{Stability in Individual Differences From Infancy to Adulthood}

Perhaps the most provocative and controversial implication of Hazan and Shaver's (1987, 1994) adult attachment theory is that a person's pattern of relating to romantic partners is shaped by his or her history of interactions with parental attachment figures. Although the idea that attachment style in relation to parents might have an influence on attachment style in romantic relationships is relatively uncontroversial, hypotheses about the source and degree of overlap between the two kinds of attachment orientations have been controversial (Baldwin \& Fehr, 1995; Cassidy, 2000; Duck, 1994; Hen-

\footnotetext{
${ }^{7}$ Within this framework, "working models" can be conceptualized in at least two different ways. They might include the automatic, mostly unconscious appraisal processes that activate the two different components of the attachment system. This is presumably what Bowlby meant when he referred to the expectations and self-protective strategics of 12-month-old infants. As such, working models might be just as characteristic of nonhuman primates as they are of human infants and adolescent and adult human lovers. In contrast, "working models" might include, instead of or in addition to the implicit processes just mentioned, fairly elaborate and conscious beliefs a person holds about the self and others. The two might be related, of course, insofar as a person's conscious beliefs and inferences about the self and others might be, in effect, "glosses" on what the person has observed himself or herself, as well as relationship partners, doing and experiencing in the course of romantic relationships.
} 
drick \& Hendrick, 1994; Klohnen \& Bera, 1998; Owens et al., 1995).

The most obvious way to answer questions about the influence of infant attachment experiences on romantic attachment patterns is longitudinal analysis. However, because the study of romantic attachment is relatively young, an extensive body of longitudinal data has yet to accumulate. There is only one longitudinal study of which we are aware that assessed the link between security at 1 year of age in the strange situation and security in adult romantic relationships. This unpublished study uncovered a correlation of .17 between these two variables (Steele, Waters, Crowell, \& Treboux, 1998).

The association between early attachment experiences and romantic attachment orientations has also been examined in retrospective studies. Hazan and Shaver (1987) found that adults who were secure in their romantic relationships were more likely to recall their childhood relationships with parents as being affectionate, caring, and accepting (see also Feeney \& Noller, 1990, and K. N. Levy, Blatt, \& Shaver, 1998). Other studies reveal concurrent overlap between security in the child-parent and romantic domains. Owens et al. (1995) assessed romantic relationship security in a sample of 45 engaged couples by administering the Current Relationship Interview (Crowell \& Owens, 1996), a relatively new instrument modeled after the content and structure of the Adult Attachment Interview (AAI; George, Kaplan, \& Main, 1996). Owens and her colleagues found that security, as assessed with the AAI, was correlated approximately .29 with security with the partner. In an unpublished study of 215 dating undergraduates, we collected self-report measures of security with a significant parental figure and a current romantic partner. The items for each domain were similarly worded, and security was scored the same way within each domain. Under these conditions, we found a correlation of .30 between the two different measures of attachment security. Thus, we tentatively conclude that attachment representations in the child-parent domain and attachment orientations in the romantic relationship domain are only moderately related at best (see Crowell, Fraley, \& Shaver, 1999, for a more systematic review).

Does the integrity of romantic attachment theory hinge on the degree to which early childhood experiences shape adult romantic attachment patterns? As argued by Hazan and Zeifman (1999), the most important proposition of the theory is that the attachment system, a system originally adapted for the ecology of infancy, continues to influence behavior, thought, and feeling in adulthood. This proposition may hold regardless of whether individual differences in the way the system is organized remain stable over a decade or more and stable across different kinds of intimate relationships. In fact, although the social and cognitive mechanisms invoked by attachment theorists imply that continuity may be the rule rather than the exception, these basic mechanisms can predict either long-run continuity or discontinuity, depending on the precise ways in which they are conceptualized (Fraley, 1999).

For example, Fraley (1999) discussed two models of continuity that make different predictions about long-term continuity even though they were derived from the same basic theoretical principles. Each model assumes that individual differences in attachment representations are shaped by variation in experiences with caregivers in early childhood and that, in turn, these early representations shape the quality of the individual's subsequent attachment experiences. However, one model assumes that existing representations are updated and revised in light of new experiences such that older representations are eventually "overwritten." Mathematical analyses revealed that this model predicts that the long-term stability of individual differences will approach zero. The second model is similar to the first but makes the additional assumption that representational models developed in the 1st year of life are preserved (i.e., they are not overwritten) and continue to influence relational behavior throughout the life course. Analyses of this model revealed that long-term stability can approach a nonzero limiting value. The important point here is that the principles of attachment theory can be used to derive developmental models that make strikingly different predictions about the long-term stability of individual differences. In light of this finding, we believe that the existence of long-term stability of individual differences should be considered an empirical issue rather than an assumption of the theory.

\section{Integration With Other Behavioral Systems}

Although Hazan and Shaver (1987) argued that romantic love involves the integration of 
three behavioral systems (attachment, caregiving, and sex), research inspired by attachment theory has primarily focused on attachment. Little attention has been devoted to caregiving and sex as they relate to attachment. Presumably, one reason for the popularity of research on the attachment system in adulthood and the relative unpopularity of research on the caregiving, sexual, and exploration systems is that Hazan and Shaver provided a measure of adult romantic attachment orientations but not a measure of the other proposed behavioral systems. In 1994, however, Kunce and Shaver devoted extensive attention to individual differences in caregiving in intimate relationships and showed that dimensions of caregiving are systematically related to attachment styles. At least two published studies have followed up Kunce and Shaver's work. Feeney (1996) administered both attachment and caregiving measures to 229 married couples and confirmed that secure attachment and "beneficial" caregiving are associated, and both contribute independently to marital satisfaction. There was also evidence in Feeney's study that attachment and caregiving have roots in different aspects of childhood experiences with parents. Carnelley, Pietromonaco, and Jaffe (1996), using slightly different measures of caregiving, found that people evidenced caregiving qualities similar to those of their parents, especially their same-sex parent, and that those qualities were associated with current relationship functioning. Carnelley et al. (1996) concluded that their results "support the idea that attachment and caregiving are central components of romantic love" (p. 257).

When Hazan and Shaver first proposed including the caregiving system in their model of romantic love, little empirical work had been done on the caregiving system in parents as it was conceptualized by Bowlby and Ainsworth. In recent years, however, this lacuna in the attachment literature has been addressed systematically by George and Solomon (e.g., 1996, 1999; Solomon \& George, 1996), who have designed a caregiving interview for parents of young children. The interview identifies parents as predominantly (a) flexible and secure, (b) rejecting, (c) uncertain, or (d) helpless. These caregiving patterns correspond fairly closely with the AAI classifications labeled (a) secure and autonomous, (b) dismissing, (c) preoccupied, and (d) unresolved with respect to attach- ment-related traumas and losses (Hesse, 1999). As with the AAI, the parental caregiving categories are highly predictive of the attachment orientation of an interviewee's child. From the standpoint of research on romantic, or pairbond, attachment, what is most interesting about George and Solomon's work is that it provides clues concerning the kinds of problems people encounter in intimate relationships when one or both partners' caregiving orientations are of the sort that naturally intensify the care recipient's insecurities. In other words, George and Solomon's research suggests new ways to study attachment- and caregiving-related dynamics in intimate relationships.

Even less work has been done to follow up Hazan and Shaver's ideas about the role of the sexual behavior system in the context of attachment and caregiving in romantic, or pair-bond, relationships. Several studies have shown that avoidant attachment is related to an "unrestricted" or promiscuous sexual orientation (e.g., Brennan, Clark, \& Shaver, 1998; Brennan \& Shaver, 1995; Fraley et al., 1998; Hill, Young, \& Nord, 1994), which (as mentioned earlier) might be one way in which avoidant individuals reduce their likelihood of becoming attached to sexual-romantic partners. In a preliminary study that has never been published, Hazan, Zeifman, and Middleton (1994) found that attachment-style measures were systematically and strongly related to the kinds of intimate sexual activities a person enjoys, with secure individuals enjoying a wide range of sexual activities (usually in the context of a long-term relationship); preoccupied individuals liking the "cuddly," affectionate aspects of intimacy more than the genital aspects; and avoidant individuals disliking those affectionate aspects (see also Brennan, Clark, \& Shaver, 1998; Brennan, Wu, \& Loev, 1998; Cyranowski \& Andersen, 1998; Fraley et al., 1998).

Yet to be considered in detail are the ways in which sexual attraction and mate choice-both the subject of much recent theorizing in evolutionary psychology (Fisher, 1998) - affect the formation of attachments. Hazan and Zeifman (1999) have speculated that sexual attraction and sexual intimacy increase the likelihood of attachment formation, just as physical proximity and intimacy seem to play a role in encouraging infant-mother attachment. Moreover, Hazan and Zeifman have speculated (following 
Carter, 1992) that the neurochemistry of attachment is similar in these cases, given that the peptide oxytocin, for example, plays a role in emotional bonding in several species and is known to increase dramatically during childbirth, nursing, and orgasm. In general, more attention needs to be paid to the place of attachment and caregiving among the "middle-level" evolutionary concepts applied to romantic, sexual, pair-bond relationships (Simpson, 1999). Instead of thinking first of attachment, attachment theory, and attachment research as they may apply to romantic relationships, it will be important to think first of these kinds of relationships and the roles in them played by attachment, caregiving, sex, and other systematic processes.

\section{Conclusion}

Over the past 12 years, attachment theory has become one of the principal theoretical frameworks for the study of intimate relationships in adulthood. Although the theory possesses a number of attractive features and has a list of empirical discoveries to its credit, the original formulation of the theory was limited in a number of respects. Our goal has been to target some of the less well-developed aspects of the theory and show how they can be improved.

A revised theory should meet the following criteria. First, it should no longer include the implicit assumption that all romantic, or couple, relationships are attachment relationships. Although the original theory did not explicitly claim that all coupled partners were attached in the technical sense, Hazan and Shaver did not really address the possibility that some partners were attached and some were not, nor did they offer a method for making this distinction empirically. Over the last few years, researchers have tackled the problem and provided preliminary but useful methods that should be included in future studies.

Second, a revised theory needs to offer one or more testable explanations for the evolution of attachment in romantic relationships. We suggested several reasons why the attachment system may have been co-opted for adult love, and we hope that future researchers will begin to test these hypotheses using comparative and phylogenetic methods.
Third, the original three-category model of individual differences has been shown to be inadequate in a number of respects. It does not differentiate between dismissingly and fearfully avoidant individuals and does not fully reflect the latent dimensional structure of individual differences in attachment orientation. Recent work suggests that a two-dimensional scheme, similar to the one described by Ainsworth et al. in their 1978 book on infant-parent attachment and reconceptualized by Bartholomew (1990) for research on adolescent and adult relationships, captures most of the meaningful variance in individual differences in orientations to romantic attachment. Interpretation of these dimensions remains controversial, however, and we have argued here for an interpretation that differs somewhat from Bartholomew's (1990) emphasis on positive and negative models of the self and others.

Recent work has also revealed the flexibility people display in relating differently to various individuals in their lives and the moderate degree of continuity in attachment style they exhibit over time. Although researchers are beginning to propose developmental and cognitive models to account for these observations, a substantial amount of work remains to be done.

Finally, valuable preliminary efforts have been made to flesh out the parts of Hazan and Shaver's theory that deal with relations among the attachment, caregiving, and sexual behavioral systems, but there are no systematic, longterm programs of research on these issues. In our opinion, the theory cannot begin to do justice to attachment-related aspects of romanticsexual relationships, especially to the unfolding of relational dynamics over time, unless all of these systems are included and elucidated.

\section{References}

Ainsworth, M. D. S. (1972). Attachment and dependency: A comparison. In J. L. Gewirtz (Ed.), Attachment and dependency (pp. 97-137). Washington, DC: Winston.

Ainsworth, M. D. S. (1982). Attachment: Retrospect and prospect. In C. M. Parkes \& J. StevensonHinde (Eds.), The place of attachment in human behavior (pp. 3-30). New York: Basic Books.

Ainsworth, M. D. S. (1991). Attachments and other affectional bonds across the life cycle. In C. M. Parkes, J. Stevenson-Hinde, \& P. Marris (Eds.), 
Attachment across the life cycle (pp. 33-51). London: Routledge.

Ainsworth, M. D. S., Blehar, M., Waters, E., \& Wall, S. (1978). Patterns of attachment. Hillsdale, NJ: Erlbaum.

Astington, J. W., Harris, P. L., \& Olson, D. R. (Eds.). (1988). Developing theories of mind. Cambridge, England: Cambridge University Press.

Baldwin, M. W., \& Fehr, B. (1995). On the instability of attachment style ratings. Personal Relationships, 2, 247-261.

Baldwin, M. W., Fehr, B., Keedian, E., Seidel, M., \& Thomson, D. W. (1993). An exploration of the relational schemata underlying attachment styles: Self report and lexical decision approaches. Personality and Social Psychology Bulletin, 19, 746754.

Bartholomew, K. (1990). Avoidance of intimacy: An attachment perspective. Journal of Social and Personal Relationships, 7, 147-178.

Bartholomew, K., \& Horowitz, L. (1991). Attachment styles among young adults: A test of a four category model. Journal of Personality and Social Psychology, 61, 226-244.

Bjorklund, D. F. (1997). The role of immaturity in human development. Psychological Bulletin, I22, 153-169.

Bowlby, J. (1980). Attachment and loss: Vol. 3, Loss: Sadness and depression. New York: Basic Books.

Bowlby, J. (1982). Attachment and loss: Vol. 1, Attachment (2nd ed.). New York: Basic Books. (Original work published 1969)

Bowlby, J. (1994). The making and breaking of affectional bonds. New York: Routledge. (Original work published 1979)

Brennan, K. A., Clark, C. L., \& Shaver, P. R. (1998). Self-report measurement of adult attachment: An integrative overview. In J. A. Simpson \& W. S. Rholes (Eds.), Attachment theory and close relationships (pp. 46-76). New York: Guilford Press.

Brennan, K. A., \& Shaver, P. R. (1995). Dimensions of adult attachment, affect regulation, and romantic relationship functioning. Personality and Social Psychology Bulletin, 21, 267-283.

Brennan, K. A., Shaver, P. R., \& Tobey, A. E. (1991). Attachment styles, gender, and parental problem drinking. Journal of Social and Personal Relationships, 8, 451-466.

Brennan, K. A., Wu, S., \& Loev, J. (1998). Adult romantic attachment and individual differences in attitudes toward physical contact in the context of adult romantic relationships. In J. A. Simpson \& W. S. Rholes (Eds.), Attachment theory and close relationships (pp. 394-428). New York: Guilford Press.

Bretherton, I., \& Munholland, K. A. (1999). Internal working models in attachment relationships: A construct revisited. In J. Cassidy \& P. R. Shaver
(Eds.), Handbook of attachment: Theory, research, and clinical applications (pp. 89-111). New York: Guilford Press.

Buss, D. M. (1994). The evolution of desire. New York: Basic Books.

Carnelley, K. B., Pietromonaco, P. R., \& Jaffe, K. (1994). Depression, working models of others, and relationship functioning. Journal of Personality and Social Psychology, 66, 127-140.

Carnelley, K. B., Pietromonaco, P. R., \& Jaffe, K. (1996). Attachment, caregiving, and relationship functioning in couples: Effects of self and partner. Personal Relationships, 3, 257-277.

Carter, C. S. (1992). Oxytocin and sexual behavior. Neuroscience and Biobehavioral Reviews, 16, 131-144.

Cassidy, J. (1999). The nature of the child's ties. In J. Cassidy \& P, R. Shaver (Eds.), Handbook of attachment: Theory, research, and clinical applications (pp. 3-21). New York: Guilford Press.

Cassidy, J. (2000). Adult romantic attachments: A developmental perspective on individual differences. Review of General Psychology, 4, 111-131.

Chappell, K. D., \& Davis, K. E. (1998). Attachment, partner choice, and perceptions of romantic partners: An experimental test of the attachment-security hypothesis. Personal Relationships, 5, 327342.

Collins, N. L. (1996). Working models of attachment: Implications for explanation, emotion, and behavior. Journal of Personality and Social Psychology, 71, 810-832.

Collins, N. L., \& Read, S. J. (1990). Adult attachment, working models, and relationship quality in dating couples. Journal of Personality and Social Psychology, 58, 644-663.

Crowell, J. A., Fraley, R. C., \& Shaver, P. R. (1999). Measurement of individual differences in adolescent and adult attachment. In J. Cassidy \& P. R. Shaver (Eds.), Handbook of attachment: Theory, research, and clinical applications (pp. 434-465). New York: Guilford Press.

Crowell, J. A., \& Owens, G. (1996). Current Relationship Interview and scoring system. Unpublished manuscript, State University of New York at Stony Brook.

Cyranowski, J. M., \& Andersen, B. L. (1998). Schemas, sexuality, and romantic attachment. Journal of Personality and Social Psychology, 74, 13641379.

Daly, M., \& Wilson, M. (1988). Homicide. New York: Aldine de Gruyter.

Davis, K. E., Kirkpatrick, L. A., Levy, M. B., \& O'Hearn, R. (1994). Stalking the elusive love style: Attachment styles, love styles, and relationship development. In R. Erber \& R. Gilmour (Eds.), Theoretical frameworks for close relationships (pp. 179-210). Hillsdale, NJ: Erlbaum. 
deBeer, G. (1958). Embryos and ancestors (3rd ed.). Oxford, England: Clarendon Press.

De Wolff, M. S., \& van IJzendoorn, M. H. (1997). Sensitivity and attachment: A meta-analysis on parental antecedents of infant attachment. Child Development, 68, 571-591.

Duck, S. (1994). Attaching meaning to attachment. Psychological Inquiry, 5, 34-38.

Feeney, J. A. (1996). Attachment, caregiving, and marital satisfaction. Personal Relationships, 3, 401-416.

Feeney, J. A. (1999). Adult romantic attachment and couple relationships. In J. Cassidy \& P. R. Shaver (Eds.), Handbook of attachment: Theory, research, and clinical applications (pp. 355-377). New York: Guilford Press.

Feeney, J. A., \& Noller, P. (1990). Attachment style as a predictor of adult romantic relationships. Journal of Personality and Social Psychology, 58, 281291.

Feeney, J. A., \& Noller, P. (1992). Attachment style and romantic love: Relationship dissolution. Australian Journal of Psychology, 44, 69-74.

Feeney, J. A., \& Noller, P. (1996). Adult attachment. Beverly Hills, CA: Sage.

Fisher, H. E. (1998). Lust, attraction, and attachment in mammalian reproduction. Human Nature, 9, 23-52.

Fraley, R. C. (1999). Attachment continuity from infancy to adulthood: Meta-analysis and dynamic modeling of developmental mechanisms. Manuscript submitted for publication.

Fraley, R. C., \& Davis, K. E. (1997). Attachment formation and transfer in young adults' close friendships and romantic relationships. Personal Relationships, 4, 131-144.

Fraley, R. C., Davis, K. E., \& Shaver, P. R. (1998). Dismissing-avoidance and the defensive organization of emotion, cognition, and behavior. In J. A. Simpson \& W. S. Rholes (Eds.), Attachment theory and close relationships (pp. 249-279). New York: Guilford Press.

Fraley, R. C., \& Shaver, P. R. (1997). Adult attachment and the suppression of unwanted thoughts. Journal of Personality and Social Psychology, 73, 1080-1091.

Fraley, R. C., \& Shaver, P. R. (1998). Airport separations: A naturalistic study of adult attachment dynamics in separating couples. Journal of Personality and Social Psychology, 75, 1198-1212.

Fraley, R. C., \& Shaver, P. R. (1999). Loss and bereavement: Attachment theory and recent controversies concerning "grief work" and the nature of detachment. In J. Cassidy \& P. R. Shaver (Eds.), Handbook of attachment: Theory, research, and clinical applications (pp. 735-759). New York: Guilford Press.
Fraley, R. C., \& Waller, N. G. (1998). Adult attachment patterns: A test of the typological model. In J. A. Simpson \& W. S. Rholes (Eds.), Attachment theory and close relationships (pp. 77-114). New York: Guilford Press.

Fraley, R. C., Waller, N. G., \& Brennan, K. A. (2000). An item response theory analysis of selfreport measures of adult attachment. Journal of Personality and Social Psychology, 78, 350-365.

Frazier, P. A., Byer, A. L., Fischer, A. R., Wright, D. M., \& DeBord, K. A. (1996). Adult attachment style and partner choice: Correlational and experimental findings. Personal Relationships, 3, 117136.

George, C., Kaplan, N., \& Main, M. (1996). The Adult Attachment Interview. Unpublished manuscript, University of California at Berkeley.

George, C., \& Solomon, J. (1996). Representational models of relationships: Links between caregiving and attachment. Infant Mental Health Journal, 17, 198-216.

George, C., \& Solomon, J. (1999). Attachment and caregiving: The caregiving behavioral system. In J. Cassidy \& P. R. Shaver (Eds.), Handbook of attachment: Theory, research, and clinical applications (pp. 649-670). New York: Guilford Press.

Griffin, D. W., \& Bartholomew, K. (1994a). The metaphysics of measurement: The case of adult attachment. In K. Bartholomew \& D. Perlman (Eds.), Advances in personal relationships: Vol. 5. Attachment processes in adulthood (pp. 17-52). London: Jessica Kingsley.

Griffin, D. W., \& Bartholomew, K. (1994b). Models of the self and other: Fundamental dimensions underlying measures of adult attachment. Journal of Personality and Social Psychology, 67, 430445.

Gubernick, D. J. (1994). Biparental care and malefemale relations in mammals. In S. Parmigiani \& F. S. vom Saal (Eds.), Infanticide and parental care (pp. 427-463). Chur, Switzerland: Harwood.

Hazan, C., \& Diamond, L. M. (2000). The place of attachment in human mating. Review of General Psychology, 4, 186-204.

Hazan, C., Hutt, M. J., Sturgeon, J., \& Bricker, T. (1991, April). The process of relinquishing parents as attachment figures. Paper presented at the biennial meeting of the Society for Research in Child Development, Seattle, WA.

Hazan, C., \& Shaver, P. (1987). Romantic love conceptualized as an attachment process. Journal of Personality and Social Psychology, 52, 511-524.

Hazan, C., \& Shaver, P. R. (1990). Love and work: An attachment theoretical perspective. Journal of Personality and Social Psychology, 59, 270-280.

Hazan, C., \& Shaver, P. R. (1994). Attachment as an organizational framework for research on close relationships. Psychological Inquiry, 5, 1-22. 
Hazan, C., \& Zeifman, D. (1994). Sex and the psychological tether. In K. Bartholomew \& D. Perlman (Eds.), Advances in personal relationships (Vol. 5, pp. 151-178). London: Jessica Kingsley.

Hazan, C., \& Zeifman, D. (1999). Pair bonds as attachments: Evaluating the evidence. In $\mathbf{J}$. Cassidy \& P. R. Shaver (Eds.), Handbook of attachment: Theory, research, and clinical applications (pp. 336-354). New York: Guilford Press.

Hazan, C., Zeifman, D., \& Middleton, K. (1994, July). Adult romantic attachment, affection, and sex. Paper presented at the 7th International Conference on Personal Relationships, Groningen, the Netherlands.

Hendrick, C., \& Hendrick, S. S. (1986). A theory and method of love. Journal of Personality and Social Psychology, 50, 392-402.

Hendrick, C., \& Hendrick, S. S. (1994). Attachment theory and close relationships. Psychological Inquiry, 5, 38-41.

Hesse, E. (1999). State of mind with respect to attachment and its effects on parenting behavior. In J. Cassidy \& P. R. Shaver (Eds.), Handbook of attachment: Theory, research, and clinical applications (pp. 395-433). New York: Guilford Press.

Hill, E. M., Young, J. P., \& Nord, J. L. (1994). Childhood adversity, attachment security, and adult relationships: A preliminary study. Ethology and Sociobiology, 15, 323-338.

Hinde, R. A. (1982). Ethology: Its nature and relations with other sciences. Oxford, England: Oxford University Press.

Hrdy, S. B. (1992). Fitness tradeoffs in the history and evolution of delegated mothering with special references to wet-nursing, abandonment, and infanticide. Ethology and Sociobiology, 13, 409442.

Insel, T. R. (2000). Toward a neurobiology of attachment. Review of General Psychology, 4, 176-185.

Kirkpatrick, L. A. (1998). Evolution, pair-bonding, and reproductive strategies: A reconceptualization of adult attachment. In J. A. Simpson \& W. S. Rholes (Eds.), Attachment theory and close relationships (pp. 353-393). New York: Guilford Press.

Kirkpatrick, L. A., \& Davis, K. E. (1994). Attachment style, gender, and relationship stability: A longitudinal analysis. Journal of Personality and Social Psychology, 66, 502-512.

Kirkpatrick, L. A., \& Hazan, C. (1994). Attachment styles and close relationships: A four-year prospective study. Personal Relationships, 1, 123142.

Klass, D., Silverman, P. R., \& Nickman, S. L. (Eds.). (1996). Continuing bonds: New understandings of grief. Washington, DC: Taylor \& Francis.

Kleiman, D. (1977). Monogamy in mammals. Quarterly Review of Biology, 52, 39-69.
Klohnen, E. C., \& Bera, S. (1998). Behavioral and experiential patterns of avoidantly and securely attached women across adulthood: A 31-year longitudinal study. Journal of Personality and Social Psychology, 74, 211-223.

Klohnen, E. C., \& John, O. P. (1998). Working models of attachment: A theory-based prototype approach. In J. A. Simpson \& W. S. Rholes (Eds.), Attachment theory and close relationships (pp. 115-140). New York: Guilford Press.

Kobak, R., Cole, H., Ferenz-Gillies, R., Fleming, W., \& Gamble, W. (1993). Attachment and emotional regulation during mother-teen problem solving: A control theory analysis. Child Development, 64, 231-245.

Komers, P. E., \& Brotherton, P. N. M. (1997). Female space use is the best predictor of monogamy in mammals. Proceedings of the Royal Society of London B, 264, 1261-1270.

Kunce, L. J., \& Shaver, P. R. (1994). An attachmenttheoretical approach to caregiving in romantic relationships. In K. Bartholomew \& D. Perlman (Eds.), Advances in personal relationships: Vol. 5. Attachment process in adulthood (pp. 205-237). London: Jessica Kingsley.

Lazarus, R. S., \& Folkman, S. (1984), Stress, appraisal, and coping. New York: Springer.

Lee, J. A. (1973). The colors of love: An exploration of the ways of loving. Toronto, Ontario, Canada: New Press.

Lee, J. A. (1988). Love-styles. In R. J. Sternberg \& M. Barnes (Eds.), The psychology of love ( $\mathrm{pp}$. 38-67). New Haven, CT: Yale University Press.

Levy, K. N., Blatt, S. J., \& Shaver, P. R. (1998). Attachment styles and parental representations. Journal of Personality and Social Psychology, 74, 407-419.

Levy, M. B., \& Davis, K. E. (1988). Lovestyles and attachment styles compared: Their relations to each other and to various relationship characteristics. Journal of Social and Personal Relationships, 5, 439-471.

Main, M. (1990). Cross-cultural studies of attachment organization: Recent studies, changing methodologies, and the concept of conditional strategies. Human Development, 33, 48-61.

Meehl, P. M. (1995). Bootstraps taxometrics: Solving the classification problem in psychopathology. American Psychologist, 50, 266-275.

Mendoza, S. P., \& Mason, W. A. (1986). Contrasting responses to intruders and to involuntary separation by monogamous and polygynous New World monkeys. Physiology and Behavior, 38, 795-801.

Mickelson, K. D., Kessler, R. C., \& Shaver, P. R. (1997). Adult attachment in a nationally representative sample. Journal of Personality and Social Psychology, 73, 1092-1106. 
Mikulincer, M. (1998). Attachment working models and the sense of trust: An exploration of interaction goals and affect regulation. Journal of Personality and Social Psychology, 74, 1209-1224.

Mikulincer, M., Florian, V., \& Tolmacz, R. (1990). Attachment styles and fear of personal death: A case study of affect regulation. Journal of Personality and Social Psychology, 58, 273-280.

Mikulincer, M., \& Orbach, I. (1995). Attachment styles and repressive defensiveness: The accessibility and architecture of affective memories. Journal of Personality and Social Psychology, 68, 917925.

Miller, L. C., \& Fishkin, S. A. (1997). On the dynamics of human bonding and reproductive success: Seeking windows on the adapted-for humanenvironmental interface. In J. A. Simpson \& D. T. Kenrick (Eds.), Evolutionary social psychology (pp. 197-235). Mahwah, NJ: Erlbaum.

Montagu, A. (1989). Growing young (2nd ed.). Grandy, MA: Bergin \& Garvey.

Owens, G., Crowell, J., Pan, H., Treboux, D., O'Connor, E., \& Waters, E. (1995). The prototype hypothesis and the origins of attachment working models: Adult relationships with parents and romantic partners. In E. Waters, B. Vaughn, G. Posada, \& K. Kondo-Ikemura (Eds.), Caregiving, cultural, and cognitive perspectives on securebase behavior and working models: New growing points of attachment theory and research (pp. 216-233). Chicago: University of Chicago Press.

Parkes, C. M., \& Weiss, R. S. (1983). Recovery from bereavement. New York: Basic Books.

Pietromonaco, P. R., \& Carnelley, K. B. (1994). Gender and working models of attachment: Consequences for perceptions of self and romantic relationships. Personal Relationships, 1, 63-82.

Pietromonaco, P. R., \& Feldman Barrett, L. (2000). The internal working models concept: What do we really know about the self in relation to others? Review of General Psychology, 4, 155-175.

Pistole, C. (1995). College students' ended love relationships: Attachment style and emotion. Journal of College Student Development, 1, 53-60.

Poirier, F. E., \& Smith, E. O. (1974). Socializing functions of primate play. American Zoologist, I4, 275-287.

Robins, R. W., Norem, J. K., \& Cheek, J. M. (1999). Naturalizing the self. In L. Pervin \& O. P. John (Eds.), Handbook of personality (2nd ed., pp. 443477). New York: Guilford Press.

Rubenstein, C., \& Shaver, P. R. (1982). In search of intimacy. New York: Delacorte.

Shaver, P. R., \& Clark, C. L. (1994). The psychodynamics of aduit romantic attachment. In J. $\mathbf{M}$. Masling \& R. F. Bornstein (Eds.), Empirical perspectives on object relations theories (pp. 105-
156). Washington, DC: American Psychological Association.

Shaver, P., \& Hazan, C. (1987). Being lonely, falling in love: Perspectives from attachment theory. Journal of Social Behavior and Personality, 2, 105-124.

Shaver, P. R., \& Hazan, C. (1988). A biased overview of the study of love. Journal of Social and Personal Relationships, 5, 473-501.

Shaver, P. R., Hazan, C., \& Bradshaw, D. (1988). Love as attachment: The integration of three behavioral systems. In R. J. Sternberg \& M. L. Bames (Eds.), The psychology of love (pp. 68-99). New Haven, CT: Yale University Press.

Sillén-Tullberg, B., \& Møller, A. P. (1993). The relationship between concealed ovulation and mating systems in anthropoid primates: A phylogenetic analysis. American Naturalist, 141, 1-25.

Simpson, J. A. (1990). The influence of attachment styles on romantic relationships. Journal of Personality and Social Psychology, 59, 971-980.

Simpson, J. A. (1999). Attachment theory in modern evolutionary perspective. In J. Cassidy \& P. R. Shaver (Eds.), Handbook of attachment: Theory, research, and clinical applications (pp. 123-150). New York: Guilford Press.

Simpson, J. A., Rholes, W. S., \& Nelligan, J. S. (1992). Support-seeking and support-giving within couple members in an anxiety-provoking situation: The role of attachment styles. Journal of Personality and Social Psychology, 62, 434-446.

Simpson, J. A., Rholes, W. S., \& Phillips, D. (1996). Conflict in close relationships: An attachment perspective. Journal of Personality and Social Psychology, 71, 899-914.

Solomon, J., \& George, C. (1996). Defining the caregiving system: Toward a theory of caregiving. Infant Mental Health Journal, 17, 183-197.

Steele, J., Waters, E., Crowell, J., \& Treboux, D. (1998, June). Self-report measures of attachment: Secure bonds to other attachment measures and attachment theory? Paper presented at the biennial meeting of the International Society for the Study of Personal Relationships, Saratoga Springs, NY.

Sternberg, R. J. (1986). A triangular theory of love. Psychological Review, 93, 119-135.

Stylianos, S. K., \& Vachon, M. L. S. (1993). The role of social support in bereavement. In M. S. Stroebe, W. Stroebe, \& R. O. Hansson (Eds.), Handbook of bereavement: Theory, research, and intervention (pp. 397-410). Cambridge, England: Cambridge University Press.

Tinbergen, N. (1963). On the aims and methods of ethology. Zeitschrift für Tierpsychologie, 20, 410433.

Trinke, S. J., \& Bartholomew, K. (1997). Hierarchies of attachment relationships in young adulthood. 
Journal of Social and Personal Relationships, 14, 603-625.

Vachon, M. L. S., Sheldon, A. R., Lancee, W. J., Lyall, W. A. L., Rogers, J., \& Freeman, S. J. J. (1982). Correlates of enduring stress patterns following bereavement: Social network, life situation, and personality. Psychological Medicine, 12, 783788.

van Doorn, C., Kasl, S. V., Beery, L. C., Jacobs, S. C., \& Prigerson, H. G. (1998). The influence of marital quality and attachment styles on traumatic grief and depressive symptoms. Journal of $\mathrm{Ner}$ vous and Mental Disease, 186, 566-573.

van IJzendoom, M. H. (1995). Adult attachment representations, parental responsiveness, and infant attachment: A meta-analysis on the predictive validity of the Adult Attachment Interview. Psychological Bulletin, 117, 387-403.

van IJzendoorn, M. H., \& DeWolff, M. S. (1997). In search of the absent father-Meta-analysis of infant-father attachment: A rejoinder to our discussants. Child Development, 68, 604-609.

van Schaik, C. P., \& Dunbar, R. I. M. (1990). The evolution of monogamy in large primates: A new hypothesis and some crucial tests. Behavior, 115, $30-62$.

Weiss, R. S. (1973). Loneliness: The experience of emotional and social isolation. Cambridge, MA: MIT Press.
Weiss, R. S. (1982). Attachment in adult life. In C. M. Parkes \& J. Stevenson-Hinde (Eds.), The place of attachment in human behavior (pp. 171184). New York: Basic Books.

Weiss, R. S. (1991). The attachment bond in childhood and adulthood. In P. Marris, J. StevensonHinde, \& C. Parkes (Eds.), Attachment across the life cycle (pp. 66-76). New York: Routledge.

Wilson, M., \& Daly, M. (1994). The psychology of parenting in evolutionary perspective and the case of human filicide. In S. Parmigiani \& F. S. vom Saal (Eds.), Infanticide and parental care (pp. 73-104). Chur, Switzerland: Harwood.

Yirmiya, N., Erel, O., Shaked, M., \& SolomonicaLevi, D. (1998). Meta-analyses comparing theory of mind abilities of individuals with autism, individuals with mental retardation, and normally developing individuals. Psychological Bulletin, 124, 283-307.

Zeifman, D., \& Hazan, C. (1997). Attachment: The bond in pair-bonds. In J. A. Simpson \& D. T. Kenrick (Eds.), Evolutionary social psychology (pp. 237-263). Mahwah, NJ: Erlbaum.

Received April 1, 1999

Revision received August 20, 1999 Accepted August 25, 1999 